\title{
Childhood Craniopharyngioma: A 22-Year Challenging Follow-Up in a Single Center
}

\section{Authors}

Patrícia Débora Cavalcanti Tosta-Hernandez ${ }^{1,2^{*}}$, Adriana Aparecida Siviero-Miachon ${ }^{1,2 *}$, Nasjla Saba da Silva², Andrea Cappellano², Marcelo de Medeiros Pinheiro ${ }^{3}$, Angela Maria Spinola-Castro1, 2

\author{
Affiliations \\ 1 Pediatric Endocrinology Division, Federal University of \\ São Paulo - UNIFESP/EPM, São Paulo, Brazil \\ 2 Pediatric Oncology Institute, Federal University of São \\ Paulo - IOP/GRAACC - UNIFESP/EPM, São Paulo, Brazil \\ 3 Rheumatology Division, Federal University of São Paulo \\ - UNIFESP/EPM, São Paulo, Brazil
}

\author{
Key words \\ obesity, body weight, hypopituitarism, adipose tissue, \\ growth hormone/deficiency \\ received 01.05 .2018 \\ accepted 05.06.2018 \\ Bibliography \\ DOI https://doi.org/10.1055/a-0641-5956 \\ Published online: 29.6.2018 \\ Horm Metab Res 2018; 50: 675-682 \\ (c) Georg Thieme Verlag KG Stuttgart · New York \\ ISSN 0018-5043 \\ Correspondence \\ Patrícia D. C. Tosta-Hernandez \\ 826 Coronel Lisboa Str. \\ São Paulo \\ ZIP 04020-041 \\ Brazil \\ Tel.: + 55/11/5579 5834, Fax: + 55/11/5579 5834 \\ pthernandez@hotmail.com, \\ aasm.dped@epm.br
}

\begin{abstract}
Craniopharyngioma is a sellar/suprasellar benign tumor whose aggressiveness may imply in endocrine disturbances (hypothalamic obesity and hormone deficiencies). Fifty-seven patients were evaluated according to clinical characteristics, hypothalamic involvement, type of treatment, anthropometric variables, adiposity indexes (body mass index Z score category at diagnosis and post-treatment, total body fat, visceral adipose tissue, and metabolic syndrome components) and analyzed through multiple regression and logistic models. Patients were stratified according to growth hormone deficiency and recombinant human growth hormone use. Mean ages at diagnosis and at study evaluation were 9.6 and 16.6 years old, respectively. A set of $43 / 57$ (75.4\%) patients presented with important hypothalamic involvement, 24/57 (42.1\%) received surgical treatment and cranial radiotherapy, and 8/57 (14\%) interferon- $\alpha$ exclusively. Fifty-five patients $(96.5 \%)$ were considered growth hormone deficient, and 26/57 (45.6\%) grew despite no recombinant human growth hormone replacement therapy. At diagnosis, 12/57 (21\%) patients were obese, and $33 / 57$ (57.9\%) at study evaluation, and after 3.2 years (median) post first therapy. There was no influence of height $Z$ score on body mass index $Z$ score. Body mass index $Z$ score at diagnosis positively influenced body mass index $Z$ score, total body fat, waist circumference and the presence of the metabolic syndrome post-treatment. Replacement of recombinant human growth hormone decreased total body fat and visceral adipose tissue. Craniopharyngioma patients worsened body mass index $Z$ score category 3.2 years (median) after first treatment. Body mass index $Z$ score increased due to real weight gain, without height decrease. Replacement of recombinant human growth hormone had beneficial effect on adiposity.
\end{abstract}

\section{Introduction}

Craniopharyngioma (CP) is a rare and benign tumor of sellar and suprasellar region with an annual incidence of $0.5-2.0$ cases per million, which represents $1-15 \%$ of all intracranial tumors [1]. It is derived from ectodermic cells of Rathke pouch and the most frequent histological type is the adamantinomatous, which is associated with mutations in CTNNB1 gene [2, 3]. Incomplete resection

* Both authors contributed equally to this work followed by adjuvant cranial radiation therapy (CRT) and/or local chemotherapy is the commonly adopted therapy [2]. In consequence of the tumor or its treatment, patients may develop visual, neurologic, hypothalamic, and endocrine disturbances, such as hypo/panhypopituitarism and hypothalamic obesity $[1,2,4,5]$.

$\mathrm{CP}$ is considered an emblematic model for hypothalamic obesity that is a devastating result of a functional damage of the hypothalamus network [6, 7]. To date, treatment for hypothalamic obesity is difficult with poor response to diet, physical exercises and/or medications, leading to an important impact on quality of life, morbidity 
and mortality [6]. As an important cause of hypothalamic obesity, CP may also lead to a higher occurrence of the components of the metabolic syndrome (MS) and consequently increased risk of cardiovascular disease (CVD) $[5,8,9]$. Thus, the goal of this study was to describe the main clinical characteristics of childhood CP patients, particularly endocrine-metabolic profile, and to evaluate factors that have possibly influenced adiposity during the follow-up.

\section{Subjects and Methods}

\section{Subjects' characteristics}

This was a cross-sectional study of a randomly selected sampling of CP patients of both sexes from the Pediatric Oncology Institute - IOP/GRAACC, Federal University of São Paulo - UNIFESP/EPM, admitted from 1992 to 2014 . The study was approved by the Ethics Research Committee of UNIFESP/EPM (No. 743.617). To participate in this study, patients or parents, when appropriate, signed an informed consent form. The inclusion criteria comprised minimal chronological age of two years at study assessment, as well as a minimal interval of six months after diagnosis, and adequate replacement of hormone deficiencies. Characteristics of host/disease and therapy were assessed from clinical examinations and/or medical records, encompassing: sex, age at diagnosis and assessment, symptoms, hypothalamic damage according to Puget criteria [10], histological type, type of treatment, hormone deficiencies, and replacement therapy schedule.

$\mathrm{CP}$ patients were treated with a combination of different procedures, as follows: total or partial tumor resection (surgery), fractionated CRT with a mean dosage of $54 \mathrm{~Gy}$, and intratumoral injection of interferon- $\alpha$ (IFN- $\alpha$ ). IFN- $\alpha$ was administered to the predominantly cystic CP through an Ommaya reservoir comprising weekly sessions of $3 \mathrm{MU}$ each at a total of $12 \mathrm{MU}$ to compose a cycle, either alone or in combination with adjuvant therapies, such as surgery and/or CRT. Adjuvant therapies were occasionally necessary when tumor relapsed [11].

Hormone deficiencies were defined according to the respective replacement therapy, comprising glucocorticoids (central hypocortisolism), levothyroxine sodium (central hypothyroidism), sexual steroids (hypogonadotropic hypogonadism), and/or desmopressin (diabetes insipidus). Growth hormone deficiency (GHD) was evaluated, and diagnosed according to the following criteria: short stature (height Z score, Z height <-2.0 standard deviation, SD) and/ or $Z$ height $<1.0$ SD below target height, growth velocity less than the 25th percentile for sex and age, negative response to growth hormone $(\mathrm{GH})$ stimulation tests (insulin and/or clonidine) $(\mathrm{GH}$ peak $\leq 5 \mu \mathrm{g} / \mathrm{I}$ ) and/or decreased insulin-like growth factor-1 (IGF1) [12-14]. All the patients presenting poor growth velocity with predicted height below target height were considered for replacement therapy with recombinant human $\mathrm{GH}(\mathrm{rhGH})$. Patients showing normal $Z$ height and adequate growth velocity despite negative response to $\mathrm{GH}$ stimulation tests and/or decreased IGF-1 did not receive $\mathrm{rhGH}$ replacement therapy. All GHD patients (except for two who were Non-GHD) were classified according to rhGH treatment in four different groups (so-called GH group): 1) Non-rh$\mathrm{GH}$ : patients with normal growth (despite GHD), and no rhGH replacement therapy; 2) rhGH-p: treated with rhGH previously to this study assessment; 3) rhGH-c: in current use of rhGH; and 4) NonrhGH-to date: patients not treated with rhGH, thus far.

\section{Adiposity indexes}

Body mass index (BMI), calculated as the weight in kilograms divided by height in meters squared $\left(\mathrm{kg} / \mathrm{m}^{2}\right)$, was converted into $Z$ scores (Z BMI), based on the World Health Organization (WHO) references $[12,13]$. Subjects were classified into categories of $Z$ BMI, as follows: normal ( $Z \mathrm{BMI}<1.0 \mathrm{SD})$, overweight $(1.0<Z$ $B M I<2.0 S D)$, obese ( $Z \mathrm{BMI}>2.0 \mathrm{SD})$, and extremely obese ( $Z$ $\mathrm{BMI}>3.0 \mathrm{SD}$ ), at diagnosis and at study evaluation (post-treatment).

Total body fat in percentage (\%TBF) was assessed using dual-energy X-ray absorptiometry (DXA), GE-Lunar Radiation corporation (iDXA, USA model), according to the standard protocol for analysis and acquisition, following the International Society for Clinical Densitometry and Brazilian Association for Evaluation of Bone Health and Osteometabolism (ABRASSO) [15, 16].

\section{Fat distribution indexes}

Waist circumference (WC) and abdominal adipose tissue, encompassing total adipose tissue (TAT) and its two layers: visceral adipose tissue (VAT) and subcutaneous adipose tissue (SAT), were measured according to the method described elsewhere $[17,18]$. The following WC cut-offs were considered for adults (over 16 years old): males at or above $94 \mathrm{~cm}$ and females at or above $80 \mathrm{~cm}$ [19]. The cut-offs were modified for children and adolescents (at or below 16 years of age), as follows: WC at or above the 90th percentile, according to the International Diabetes Federation (IDF) [20]. Data by Freedman et al. from the Bogalusa Study [21] were used to generate the WC percentiles.

\section{Blood pressure}

Systolic blood pressure (SBP) and diastolic blood pressure (DBP) (in $\mathrm{mmHg}$ ) were both measured with the patient in the sitting position after five minutes of rest in a tranquil environment, by auscultation, average of three outlets in the right $\operatorname{arm}\left(\operatorname{Tycos}^{\circledR}\right)$. Hypertension was considered in adults ( $\geq 18$ years) if SBP $\geq 130 \mathrm{mmHg}$ and/or DBP $\geq 85 \mathrm{mmHg}$ or use of antihypertensive drug [19]; and for children and adolescents ( $<18$ years) if SBP and/or DBP were at or above the 95th percentile, according to height, sex and age, following the indications of the National High Blood Pressure Education Program Working Group on High Blood Pressure in Children and Adolescents [22].

\section{Metabolic profile and growth factor}

Blood samples were collected after a 12-h overnight fast, to assess the metabolic profile. Fasting glucose was assayed using an automated method and insulin levels in duplicate using ACTIVE ${ }^{\circledR}$ Insulin ELISA DSL-10-1600 (Diagnostics Systems Laboratories, Inc., Webster, Texas, USA), having an intra- and inter-assay coefficient of variability (CV) of $2 \%$ and $5 \%$, respectively, minimum detection limit of $2.08 \mathrm{pmol} / \mathrm{l}$, and specificity of $100 \%$. Altered glucose level was defined according to Genuth et al. [23]. To determine insulin sensitivity, glucose and insulin levels were assessed to calculate the homeostatic model assessment - insulin resistance (HOMA1-IR) [24]. With the aim of defining insulin resistance, cut-off values for 
HOMA1-IR were assigned as: adults (> 18 years) $>2.7$ [25], and children and adolescents ( $\leq 18$ years) $>3.4$ [26].

Total cholesterol, high-density lipoprotein-cholesterol (HDL-c), and triglycerides (TG) were determined using a colorimetric enzymatic method. Low-density lipoprotein-cholesterol (LDL-c) was calculated by the formula described by Friedewald et al. [27]. Concerning HDL-c and TG levels, the following cut-offs were considered as dyslipidemia: HDL-c $<1.04 \mathrm{mmol} / \mathrm{l}$ (for adults, $>19$ years) and $<1.17 \mathrm{mmol} / \mathrm{l}$ (for children and adolescents, $\leq 19$ years); TG $>2.26 \mathrm{mmol} / \mathrm{l}$ and $\geq 1.47 \mathrm{mmol} / \mathrm{l}$, for adults and children and adolescents, respectively $[28,29]$.

IGF-1 (in nmol/I) was analyzed by a sandwich assay, one-step chemiluminescence using coated magnetic microparticles (LIAISON ${ }^{\circledR}$ IGF-1 OS-313, 231, Gruppe Biomedica, Inc., Vienna, Austria), whose intra- and inter-assay CV were, respectively, $3.7 \%$ and $4.6 \%$, minimum detection limit of $0.39 \mathrm{nmol} / \mathrm{l}$ and $100 \%$ of specificity.

\section{Metabolic syndrome}

The IDF criteria were considered for evaluation. Subjects at and above 10 years old were included in the analysis following the limitations of the consensus $[19,20]$. The following variables were analyzed, as determined in the conditions: WC $(\mathrm{cm}), \mathrm{HDL}-\mathrm{c}(\mathrm{mmol} / \mathrm{l})$, TC $(\mathrm{mmol} / \mathrm{l})$, SBP, DBP $(\mathrm{mmHg})$, and glucose $(\mathrm{mmol} / \mathrm{l})$.

\section{Statistical analyses}

Means and SDs were used to summarize the numerical variables and frequency counts and percentages to describe the categorical variables. A linear mixed effect model was used to study the effect of Z height on Z BMI over time. The normal distribution of data was verified by the Kolmogorov-Smirnov test.

A multiple linear regression was utilized to analyze the simultaneous effects of the variables in each of the dependent variables ( $Z$ BMI, \%TBF and VAT). For the initial model, variables considered significant at the $10 \%$ level were selected and/or those that appear to have a better fit. Initially, all predictive variables selected were included. Afterward, variables not significant at the $5 \%$ level were excluded one by one in a backward method. Pearson correlation was performed in order to select numerical variables. This test verifies the linear association between variables (age, number and type of treatment, hormone replacement and Z BMI at diagnosis). Additionally, to select categorical variables, Student's t-test for independent samples or one-way analysis of variance (ANOVA) were used to compare means between two or more groups, respectively (sex, GH group, and Z BMI category at diagnosis). The normal distribution of data was verified by the Kolmogorov-Smirnov test. In case of violation of the normality supposition, the non-parametric Mann-Whitney test or the Kruskal-Wallis test were alternatively utilized to compare two or more means, respectively. When mean differences were detected, the following post-tests were performed: Duncan multiple comparison and Dunn-Bonferroni, with $5 \%$ of significance global level.

Logistic regression was utilized to simultaneously evaluate the effects of the following variables: sex, age at diagnosis, GH group, and Z BMI category at diagnosis for each dependent variable (WC cut-offs and the presence of MS). Initially, all predictive variables were included in the model. Afterward, variables not significant at the $5 \%$ level were excluded one by one in a backward method. Hos- mer and Lemeshow tests were utilized to verify the adequacy adjustment of the model. In order to select numerical variables (age at diagnosis, time since diagnosis, number and type of treatment and hormone replacement) a Student's t-test for independent samples was initially utilized. This test has as assumption the normality in the distribution of data and homocedasticity, verified by Kolmogorov-Smirnov and Levene tests, respectively. In case of violation of the normality supposition, the non-parametric Mann-Whitney test was used. In case of supposition of violation of homocedasticity, Brown-Forsythe correction was used. In addition, to select categorical variables (sex, age group at diagnosis, hormone replacement, Z BMI category at diagnosis and post-treatment, and $\mathrm{GH}$ group) Chi-square or Fisher test was utilized.

The significance level was set at 0.050 . Statistical analyses were performed using SPSS 20.0 (SPSS, Inc., Chicago, IL, USA) and Stata 12.5.

\section{Results}

\section{Subjects' characteristics}

The selected sample consisted of 57 childhood CP patients, chosen from 108 medical records, 35/57 (61.4\%) males. The age at study assessment and at diagnosis was respectively [mean (SD)] 16.6 (6.3) and 9.6 (4.2) years. At diagnosis, 51/57 (89.5\%) patients had neurological and visual disturbances, 4/57 (7\%) presented with short stature and 5/57 (8.8\%) with diabetes insipidus. Forty-three out of 57 (75.4\%) were categorized as grade 2 of hypothalamic involvement. All patients were classified as adamantinomatous histological type ( $\triangleright$ Table $\mathbf{1})$.

Surgery followed by CRT was the most frequent type of therapy in 24/57 (42.1\%). Eight out of 57 (14\%) patients received IFN- $\alpha$ as monotherapy. Regarding hormone replacement, 54/57 (94.7\%) received at least two hormones (excluding $\mathrm{rhGH}$ ). In relation to $\mathrm{GH}$ group, 26/57 (45.6\%) CP subjects were classified as Non-rhGH, and 14/57 (24.6\%) were classified as rhGH-c (

\section{Adiposity indexes and fat distribution}

Concerning Z BMI, 12/57 (21\%) and 33/57 (57.9\%) CP patients were considered obese at diagnosis and at study assessment, respectively, with a median interval of 3.2 years to worse Z BMI category. In relation to WC cut-off points, 39/57 (68.4\%) patients presented with increased WC ( $\triangleright$ Table 2$)$.

\section{Metabolic variables}

No patient had either glucose intolerance or diabetes, while $\mathrm{HO}$ MA1-IR was above normal limits in 25/55 (45.4\%) patients. Lipid profile showed high levels of LDL-c in 14/57 (24.5\%), low levels of HDL-c in 28/57 (49.1\%), and high levels of TG in 23/57 (40.3\%) of CP patients ( $\triangleright$ Table 2 ).

\section{Metabolic syndrome}

Twenty-two out of $50 \mathrm{CP}$ patients who were above 10 years of age (44\%) were classified as having MS, being 11/22 (50\%) males. In children and adolescents (10-16 years), the components of MS were TG + HDL-c + WC ( $40 \%)$, while in adults (>16 years) the most important parameters were TG + HDL-c + blood pressure (33\%). 
- Table 1 Subjects' characteristics, including hypothalamic involvement, therapy, and hormone deficits of 57 patients with craniopharyngioma.

\begin{tabular}{|c|c|c|}
\hline Variables & Total & $\%$ \\
\hline \multicolumn{3}{|l|}{ Sex } \\
\hline $\mathrm{n}$ & 57 & 100 \\
\hline Male & 35 & 61.4 \\
\hline Female & 22 & 38.6 \\
\hline \multicolumn{3}{|l|}{ Hypothalamic involvement at diagnosis } \\
\hline $\mathrm{n}$ & 57 & 100 \\
\hline Grade 0 & 0 & 0 \\
\hline Grade 1 & 3 & 5.3 \\
\hline Grade 2 & 43 & 75.4 \\
\hline Not available & 11 & 19.3 \\
\hline \multicolumn{3}{|l|}{ Type of treatment } \\
\hline $\mathrm{n}$ & 57 & 100 \\
\hline Surgery & 6 & 10.5 \\
\hline CRT & 1 & 1.7 \\
\hline IFN- $\alpha$ & 8 & 14 \\
\hline Surgery + CRT + IFN $-\alpha$ & 12 & 21.2 \\
\hline Surgery + IFN- $\alpha^{a}$ & 5 & 8.8 \\
\hline Surgery+ CRT & 24 & 42.1 \\
\hline None & 1 & 1.7 \\
\hline \multicolumn{3}{|l|}{ Hormone replacement } \\
\hline $\mathrm{n}$ & 57 & 100 \\
\hline $\mathrm{GC}+\mathrm{LT}_{4}+\mathrm{E}_{2} /$ testosterone + desmopressin & 24 & 42.1 \\
\hline $\mathrm{GC}+\mathrm{LT}_{4}+$ desmopressin & 19 & 33.3 \\
\hline $\mathrm{GC}+\mathrm{LT}_{4}+\mathrm{E}_{2} /$ testosterone & 5 & 8.8 \\
\hline $\mathrm{GC}+\mathrm{LT}_{4}$ & 3 & 5.3 \\
\hline $\mathrm{GC}+\mathrm{E}_{2} /$ testosterone + desmopressin & 1 & 1.7 \\
\hline $\mathrm{LT}_{4}+$ desmopressin & 2 & 3.5 \\
\hline None & 3 & 5.3 \\
\hline \multicolumn{3}{|l|}{ GH group } \\
\hline $\mathrm{n}$ & 57 & 100 \\
\hline Non-rhGH & 26 & 45.6 \\
\hline rhGH-p & 8 & 14.0 \\
\hline rhGH-c & 14 & 24.6 \\
\hline Non-rhGH-to date & 7 & 12.3 \\
\hline Non-GHD & 2 & 3.5 \\
\hline
\end{tabular}

CRT: Cranial radiation therapy; IFN- $\alpha$ : Interferon- $\alpha$; GC: Glucocorticoid; $\mathrm{LT}_{4}$ : Levothyroxine sodium; $\mathrm{E}_{2}$ : Estrogen; $\mathrm{GH}$ : Growth hormone; rhGH: Recombinant human growth hormone; rhGH-p: Previous use of rhGH; rhGH-c: Current use of rhGH; a 1 patient also received intratumoral bleomycin; ${ }^{\mathrm{b}} 2$ patients also received intratumoral bleomycin.

\section{Regression models}

A linear-mixed effect model, which considered Z BMI and Z height at diagnosis was not significant $(p=0.770)$. The final models for all the following parameters are presented here ( $\triangleright$ Table 3 ).

\section{Z BMI}

Only Z BMI at diagnosis positively determined Z BMI at study assessment $(\beta=0.36 ; p=0.005)$.

\section{$\%$ TBF}

The following parameters positively determined \%TBF: female sex $(\beta=5.56 ; p=0.005)$ and $Z B M I$ at diagnosis $(\beta=2.01 ; p<0.001)$, while rhGH-c patients presented with a decrease in $\% \operatorname{TBF}(\beta=-6.58$; $\mathrm{p}=0.002$ ).

\section{VAT}

Age at study evaluation positively influenced VAT $(\beta=10.7$; $\mathrm{p}<0.001)$, while rhGH-c patients presented with a decrease in VAT $(\beta=-75.21 ; p=0.038)$.

\section{WC}

The following parameters positively determined WC: female sex $(O R=9.67 ; p=0.042)$, age at diagnosis (Odds ratio, $O R=1.36$; $\mathrm{P}=0.039)$, and $\mathrm{ZBMI}$ category at diagnosis $\left(\mathrm{OR}_{\text {overweight }}=23.28\right.$; $p=0.013$ and $O R_{\text {obese }}=37.23 ; p=0.019$ ).

Presence of MS

Female sex $(O R=4.14 ; p=0.038)$ and $Z$ BMI category at diagnosis $\left(O R_{\text {obese }}=6.11 ; \mathrm{p}=0.031\right)$ positively determined the presence of MS.

\section{Discussion}

This study focused on the principal characteristics of CP patients and the consequences of the disease and its treatment that could have influenced adiposity. The main finding was that Z BMI at diagnosis positively influenced post-treatment variables related to adiposity and metabolic changes (Z BMI at study assessment, WC, \%TBF, and the presence of MS).

Some presenting symptoms, such as polyuria and polydipsia, short stature and weight gain were less frequent, than described by other authors $[1,30]$. However, it was not possible to precisely establish the percentage of patients with hormone deficiencies, as few CP patients had this evaluation at diagnosis. According to literature, $40-87 \%$ of patients may have at least one hormone deficiency at diagnosis [30]. Nonetheless, the great variety of results suggests that, similarly to this study, other groups are not able to make routinely hormone dosages previously to treatment. During the post-treatment period, nearly $95 \%$ of CP subjects had two or more hormone deficiencies (excluding $\mathrm{rhGH}$ ), being approximately $80 \%$ with permanent diabetes insipidus [10,31-33]. In relation to $\mathrm{GH}$, near the totality of patients $(96.5 \%)$ had GHD, which is comparable to the literature. The non-rhGH group comprised $45.6 \%$, which is comparable to some authors [8], while increased compared to other authors, varying from $15-66 \%[34,35]$. This group mentioned above comprised the so-called "growth without $\mathrm{GH}$ ", which is a phenomenon described more than five decades ago, not completely understood, being some hormones, such as leptin and/ or insulin, playing the main role in the process [30].

The percentage of obese patients at diagnosis and at study assessment was 21 and $57.9 \%$, respectively, which is in accordance with previous studies $[31,36]$. It is important to emphasize that the increase in BMI occurred due to real weight gain, with no influence 
- Table 2 Anthropometric characteristics, adiposity indexes, and fat distribution of 57 patients with craniopharyngioma.

\begin{tabular}{|c|c|c|c|c|c|c|c|c|}
\hline \multirow{3}{*}{ Variables } & \multicolumn{8}{|c|}{ Total $(n=57)$} \\
\hline & \multicolumn{4}{|c|}{ At diagnosis } & \multicolumn{4}{|c|}{ At study evaluation } \\
\hline & Mean & SD & Min & Max & Mean & SD & Min & Max \\
\hline Weight Z score & -0.15 & 1.51 & -3.77 & 2.89 & 1.00 & 1.56 & -3.58 & 3.12 \\
\hline Height Z score & -0.99 & 1.45 & -4.63 & 2.34 & -1.08 & 1.21 & -3.85 & 2.83 \\
\hline BMI $\left(\mathrm{kg} / \mathrm{m}^{2}\right)$ & 19.8 & 5.3 & 9.0 & 31.7 & 29.1 & 8.3 & 13.5 & 50.6 \\
\hline BMI Z score & 0.80 & 1.70 & -5.50 & 4.80 & 2.10 & 1.70 & -2.00 & 7.10 \\
\hline WC $(\mathrm{cm})$ & - & - & - & - & 97.3 & 18.7 & 56.0 & 133.0 \\
\hline$\% \mathrm{TBF}$ & - & - & - & - & 42.8 & 7.8 & 18.2 & 57.1 \\
\hline $\operatorname{VAT}\left(\mathrm{cm}^{3}\right)$ & - & - & - & - & 291.0 & 555.0 & 15.6 & 4221.0 \\
\hline SAT $\left(\mathrm{cm}^{3}\right)$ & - & - & - & - & 616.0 & 361.0 & 73.9 & 1478.0 \\
\hline Glucose (mmol/l) & - & - & - & - & 4.35 & 0.48 & 2.44 & 5.44 \\
\hline HOMA1-IR & - & - & - & - & 3.76 & 2.95 & 0.20 & 15.20 \\
\hline LDL-c (mmol/l) & - & - & - & - & 2.88 & 0.91 & 0.67 & 5.26 \\
\hline HDL-c (mmol/l) & - & - & - & - & 1.05 & 0.32 & 0.26 & 2.18 \\
\hline TG $(\mathrm{mmol} / \mathrm{l})$ & - & - & - & - & 1.73 & 0.96 & 0.36 & 4.84 \\
\hline SBP (mmHg) & - & - & - & - & 102.4 & 16.7 & 80.0 & 157.0 \\
\hline $\mathrm{DBP}(\mathrm{mmHg})$ & - & - & - & - & 71.2 & 12.6 & 47.0 & 110.0 \\
\hline IGF-1 (nmol/I) & - & - & - & - & 16.10 & 17.24 & 0.39 & 81.22 \\
\hline
\end{tabular}

SD: Standard deviation; Min: Minimum; Max: Maximum; BMI: Body mass index; WC: Waist circumference; TBF: Total body fat; VAT: Visceral adipose tissue; SAT: Subcutaneous adipose tissue; HOMA1-IR: Homeostasis model assessment - insulin resistance; LDL-c: Low-density lipoprotein-cholesterol; HDL-c: High-density lipoprotein-cholesterol; TG: Triglycerides; SBP: Systolic blood pressure; DBP: Diastolic blood pressure; IGF-1: Insulin-like growth factor-1.

of Z height. Different factors could have influenced weight gain process, as follows: size and location of the tumor, invasion of supra-sellar region and hypothalamus, hypothalamic damage, dose of CRT, and genetic predisposition [6, 7,37]. In this study, hypothalamic damage at diagnosis was not identified as a factor that could have distinguished patients, and postsurgical damage was not assessed, so far [10]. In relation to CRT, a mean dosage of $54 \mathrm{~Gy}$ (fractionated doses) was part of the treatment in $73.8 \%$ of CP patients, and may have contributed to the increase of obesity rate in this sample. One may speculate if obesity may be a consequence of therapeutic procedures worsened by genetic predisposition or tumor aggressiveness. It is difficult to establish the real effect of the tumor itself or of the treatment on weight gain process. Nevertheless, it was not possible to determine a cause and effect relationship between obesity and CRT, so far $[6,36]$.

As regards Z BMI at diagnosis, this index was important to influence many post-treatment variables, such as Z BMI at study assessment, WC, \%TBF, and the presence of MS. The relation between Z $\mathrm{BMI}$ at diagnosis and post-treatment was also observed in other studies in which the authors believed that the pathogenic mechanisms for obesity were present in the early course of the disease, and related with anterior and/or posterior hypothalamic involvement $[1,32,38]$. Correspondingly, female sex positively deter- mined WC, \% $\mathrm{TBF}$, and the occurrence of MS, which is in accordance with previous studies that confirm this sexual dimorphism [5].

The rhGH-c group presented a decrease in \%TBF and VAT, which is in accordance with previous data that showed a decline in adiposity or even that rhGH replacement may prevent additional fat gain. Nonetheless, the beneficial effect of rhGH therapy on adiposity was not confirmed by some authors possibly due to a decreased sensitivity to rhCH actions along with a tendency to accumulate fat mass $[8,9,33,39]$.

As regards metabolic parameters, no patient had altered fasting glucose levels, even though $45.4 \%$ presented with altered HOMA1-IR. In relation to lipid profile, in this study, LDL-c was increased by $24.5 \%$, TG by $40.3 \%$, and HDL-c was decreased by $49.1 \%$. In the study of Nogueira et al. [32], the frequency of abnormal LDL-c was higher when compared to the present study (70\% vs. $24.5 \%)$.

Concerning the presence of MS, $44 \%$ of CP patients above 10 years of age presented with MS itself, which concurs with previous studies $[8,40]$. Srinivasan et al. [8] was the first to demonstrate the occurrence of MS in CP patients and to correlate this finding with abdominal fat and adverse lipid profile. It is also important to emphasize that the high rate of MS among this population is a warning about the high risk of CVD, which may be worsened by the hypothalamic damage and resulting hormone deficiencies [40]. 


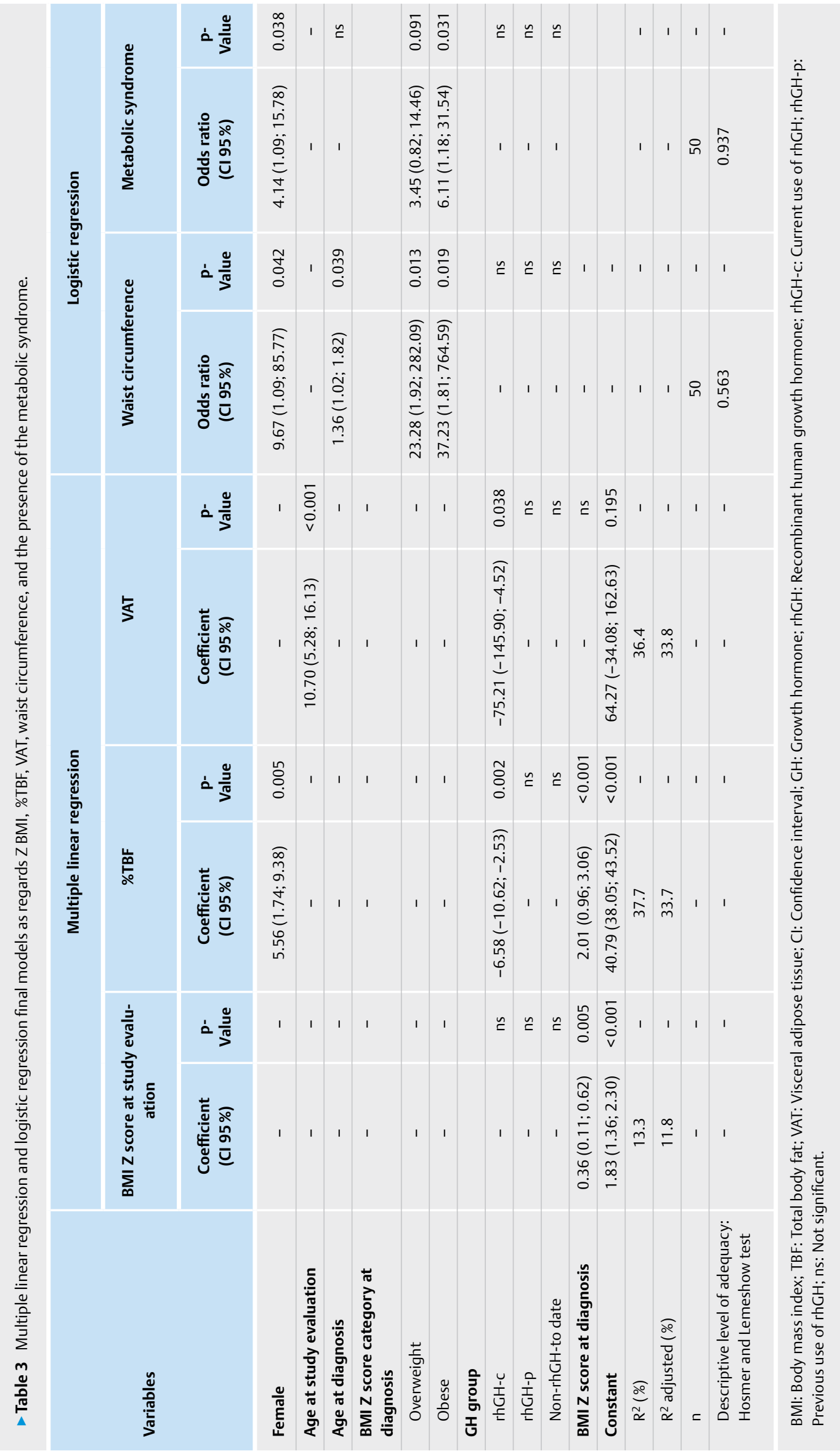


The limitations of the present study encompass the lack of initial endocrine evaluation, the absence of a clear differentiation of the grade of hypothalamic damage pre- and post-treatment, the limited size of this sample, and the great heterogeneity based on different treatment approaches, and long recruitment period.

As final considerations, the majority of childhood CP patients developed obesity after treatment. Z BMI at diagnosis influenced post-treatment variables, such as Z BMI at study assessment, WC, \%TBF and the presence of MS, while rhGH replacement decreased \%TBF and VAT. CP subjects may have serious endocrine-metabolic consequences leading to higher CVD risk. Efforts should be done in order to make a more precocious diagnosis and to perform less invasive therapies to maximize the hypothalamic-pituitary integrity, and consequently to avoid devastating longterm endocrine-metabolic adverse effects.

\section{Acknowledgements}

The authors greatly thank the patients and their families. The authors appreciate the support of Ricardo Silva Ribeiro for performing the abdominal fat layer measurements, and the statistical analyses by Mitti Koyama. This work was presented in part at the 10th International Meeting of Pediatric Endocrinology (IMPE), 2017, Washington D.C., USA.

\section{Conflict of Interest}

The authors declare that they have no conflict of interest.

\section{References}

[1] Müller HL, Emser A, Faldum A, Bruhnken G, Etavard-Gorris N, Gebhardt U, Oeverink R, Kolb R, Sörensen N. Longitudinal study on growth and body mass index before and after diagnosis of childhood craniopharyngioma. J Clin Endocrinol Metab 2004; 89: 3298-3305

[2] Karavitaki N, Cudlip S, Adams CB, Wass JA. Craniopharyngiomas. Endocr Rev 2006; 27: 371-397

[3] Martinez-Barbera JP, Andoniadou CL. Concise review: paracrine role of stem cells in pituitary tumors: a focus on adamantinomatous craniopharyngioma. Stem Cells 2016; 34: 268-276

[4] Müller HL. Consequences of craniopharyngioma surgery in children. J Clin Endocrinol Metab 2011; 96: 1981-1991

[5] Erfurth EM. Endocrine aspects and sequel in patients with craniopharyngioma. J Pediatr Endocrinol Metab 2015; 28: 19-26

[6] Müller HL. Craniopharyngioma and hypothalamic injury: Latest insights into consequent eating disorders and obesity. Curr Opin Endocrinol Diabetes Obes 2016; 23: 81-89

[7] Lustig RH. Hypothalamic obesity after craniopharyngioma: mechanisms, diagnosis, and treatment. Front Endocrinol (Lausanne) 2011; 2: 60

[8] Srinivasan S, Ogle GD, Garnett SP, Briody JN, Lee JW, Cowell CT. Features of the metabolic syndrome after childhood craniopharyngioma. J Clin Endocrinol Metab 2004; 89: 81-86

[9] Ferraù F, Spagnolo F, Cotta OR, Cannavò L, Alibrandi A, Russo GT, Aversa T, Trimarchi F, Cannavò S. Visceral adiposity index as an indicator of cardiometabolic risk in patients treated for craniopharyngioma. Endocrine 2017; 58: 295-302
[10] Puget S, Garnett M, Wray A, Grill ], Habrand JL, Bodaert N, Zerah M, Bezerra M, Renier D, Pierre-Kahn A, Saint-Rose C. Pediatric craniopharyngiomas: Classification and treatment according to the degree of hypothalamic involvement. J Neurosurg 2007; 106 (1 Suppl): 3-12

[11] Cavalheiro S, Dastoli PA, Silva NS, Toledo S, Lederman H, Silva MC. Use of interferon alpha in intratumoral chemotherapy for cystic craniopharyngioma. Childs Nerv Syst 2005; 21: 719-724

[12] WHO Child Growth Standards. Length/height-for-age, weight-for-age, weight-for-length, weight-for-height and body mass index-for-age: Methods and development. Geneva: World Health Organization; 2006: 312 pages Accessed April 21, 2018 http://www.who.int/childgrowth/ standards/Technical_report.pdf?ua $=1$

[13] De Onis M, Onyango AW, Borghi E, Siyam A, Nishida C, Siekmann ]. Development of a WHO growth reference for school-aged children and adolescents. Bulletin of the World Health Organization 2007; 85: 660-667

[14] Rogol AD, Hayden GF. Etiologies and early diagnosis of short stature and growth failure in children and adolescents. J Pediatr 2014; 164 (5 Suppl): S1-14.e6

[15] Goodpaster BH. Measuring body fat distribution and content in humans. Curr Opin Clin Nutr Metab Care 2002; 5: 481-487

[16] McCarthy HD, Cole T], Fry T, Jebb SA, Prentice AM. Body fat reference curves for children. Int J Obes (Lond) 2006; 30: 598-602

[17] World Health Organization. Waist circumference and waist-hip ratio. Report of a WHO expert consultation. Geneva, 8-11 December 2008 (39 pages). Accessed April 21, 2018 www.who.int/nutrition/ publications/obesity/WHO_report_waistcircumference_and_waisthip_ratio/en/

[18] Siviero-Miachon AA, Spinola-Castro AM, Lee ML, Andreoni S, Geloneze B, Lederman H, Guerra-Junior G. Cranial radiotherapy predisposes to abdominal adiposity in survivors of childhood acute lymphocytic leukemia. Radiat Oncol 2013; 8: 39

[19] Alberti KG, Zimmet P, Shaw ]. Metabolic syndrome - a new world-wide definition. A Consensus Statement from the International Diabetes Federation. Diabet Med 2006; 23: 469-480

[20] Zimmet P, Alberti KG, Kaufman F, Tajima N, Silink M, Arslanian S, Wong G, Bennett P, Shaw J, Caprio S.IDF Consensus Group. The metabolic syndrome in children and adolescents - an IDF consensus report. Pediatr Diabetes 2007; 8: 299-306

[21] Freedman DS, Serdula MK, Srinivasan SR, Berenson GS. Relation of circumferences and skinfold thicknesses to lipid and insulin concentrations in children and adolescents: The Bogalusa Heart Study. Am J Clin Nutr 1999; 69: 308-317

[22] National High Blood Pressure Education Program Working Group on High Blood Pressure in Children and Adolescents. The fourth report on the diagnosis, evaluation, and treatment of high blood pressure in children and adolescents. Pediatrics 2004; 114 (2 Suppl): 4th Report 555-576

[23] Genuth S, Alberti KG, Bennett P, Buse J, Defronzo R, Kahn R, Kitzmiller ], Knowler WC, Lebovitz H, Lernmark A, Nathan D, Palmer J, Rizza R, Saudek C, Shaw J, Steffes M, Stern M, Tuomilehto J, Zimmet P. Expert Committee on the Diagnosis and Classification of Diabetes Mellitus. Follow-up report on the diagnosis of diabetes mellitus. Diabetes Care 2003; 26: 3160-3167

[24] Matthews DR, Hosker JP, Rudenski AS, Naylor BA, Treacher DF, Turner RC. Homeostasis model assessment: Insulin resistance and beta-cell function from fasting glucose and insulin concentrations in man. Diabetologia 1985; 28: 412-419

[25] Geloneze B, Tambascia MA. [Laboratorial evaluation and diagnosis of insulin resistance]. Arq Bras Endocrinol Metabol 2006; 50: 208-215

[26] García Cuartero B, García Lacalle C, Jiménez Lobo C, González Vergaz A, Calvo Rey C, Alcázar Villar M], Díaz Martínez E. [The HOMA and QUICKI indexes, and insulin and C-peptide levels in healthy children. Cut off points to identify metabolic syndrome in healthy children]. An Pediatr (Barc) 2007; 66: 481-490 
[27] Friedewald WT, Levy RI, Fredrickson DS. Estimation of the concentration of low-density lipoprotein cholesterol in plasma, without use of the preparative ultracentrifuge. Clin Chem 1972; 18: 499-502

[28] Xavier HT, Izar MC, Faria Neto JR, Assad MH, Rocha VZ, Sposito AC, Fonseca FA, dos Santos JE, Santos RD, Bertolami MC, Faludi AA, Martinez TLR, Diament J, Guimarães A, Forti NA, Moriguchi E, Chagas AC, Coelho OR, Ramires ]A. [V Brazilian Guidelines on Dyslipidemias and Prevention of Atherosclerosis]. Arq Bras Cardiol 2013; 101: (Suppl 1): $1-20$

[29] Giuliano Ide C, Coutinho MS, Freitas SF, Pires MM, Zunino JN, Ribeiro RQ. [Serum lipids in school kids and adolescents from Florianópolis, SC, Brazil--Healthy Floripa 2040 study]. Arq Bras Cardiol 2005; 85: 85-91

[30] Daubenbüchel AM, Müller HL. Neuroendocrine disorders in pediatric craniopharyngioma patients. J. Clin Med 2015; 4: 389-413

[31] Cohen M, Bartels U, Branson H, Kulkarni AV, Hamilton J. Trends in treatment and outcomes of pediatric craniopharyngioma, 1975-2011. Neuro Oncol 2013; 15: 767-774

[32] Nogueira MC, Berbel Júnior AS, Koenigkam-Santos M, Moreira AC, Nonino CB, Castro M. Nutritional and endocrinologic evaluation of patients with Craniopharyngioma. Clinical Nutrition ESPEN 2015; 10: e213-e218

[33] Holmer H, Ekman B, Björk J, Nordstöm CH, Popovic V, Siversson A, Erfurth EM. Hypothalamic involvement predicts cardiovascular risk in adults with childhood onset craniopharyngioma on long-term $\mathrm{GH}$ therapy. Eur J Endocrinol 2009; 161: 671-679

[34] Simoneau-Roy J, O'Gorman C, Pencharz P, Adeli K, Daneman D, Hamilton J. Insulin sensitivity and secretion in children and adolescents with hypothalamic obesity following treatment for craniopharyngioma. Clin Endocrinol (Oxf) 2010; 72: 364-370
[35] Cohen M, Syme C, McCrindle BW, Hamilton J. Autonomic nervous system balance in children and adolescents with craniopharyngioma and hypothalamic obesity. Eur J Endocrinol 2013; 168: 845-852

[36] Rosenfeld A, Arrington D, Miller J, Olson M, Gieseking A, Etzl M, Harel B, Schembri A, Kaplan A. A review of childhood and adolescent craniopharyngiomas with particular attention to hypothalamic obesity. Pediatr Neurol 2014; 50: 4-10

[37] Wang KW, Fleming A, Johnston DL, Zelcer SM, Rassekh SR, Ladhani S, Socha A, Shinuda J, Jaber S, Burrow S, Singh SK, Banfield L, de Souza RJ, Thabane L, Samaan MC. Overweight, obesity and adiposity in survivors of childhood brain tumours: A systematic review and meta-analysis. Clin Obes 2018; 8: 55-67

[38] Müller HL, Faldum A, Etavard-Gorris N, Gebhardt U, Oeverink R, Kolb R, Sörensen N. Functional capacity, obesity and hypothalamic involvement: Cross-sectional study on 212 patients with childhood craniopharyngioma. Klin Padiatr 2003; 215: 310-314

[39] Verhelst ], Kendall-Taylor P, Erfurth EM, Price DA, Geffner M, Koltowska-Häggström M, Jönsson PJ, Wilton P, Abs R. Baseline characteristics and response to 2 years of growth hormone $(\mathrm{GH})$ replacement of hypopituitary patients with $\mathrm{GH}$ deficiency due to adult-onset craniopharyngioma in comparison with patients with nonfunctioning pituitary adenoma: Data from KIMS (Pfizer International Metabolic Database). J Clin Endocrinol Metab 2005; 90: 4636-4643

[40] Wijnen M, Olsson DS, van den Heuvel-Eibrink MM, Hammarstrand C, Janssen JAMJL, van der Lely AJ, Johannsson G, Neggers SJCMM. The metabolic syndrome and its components in 178 patients treated for craniopharyngioma after 16 years of follow-up. Eur J Endocrinol 2018; 178: $11-22$ 